\title{
Simulation of the power supply system of the coal mine section
}

\author{
Fedor Nepsha ${ }^{1,2 *}$, Vyacheslav Voronin ${ }^{1}$, Aleksei Khoreshok ${ }^{1}$, and Aleksandr Ermakov ${ }^{1}$ \\ ${ }^{1}$ T.F. Gorbachev Kuzbass State Technical University, 650000 Kemerovo, 28 Vesennya st., Russian \\ Federation \\ ${ }^{2}$ INTELAB Ltd, Moscow, Russian Federation
}

\begin{abstract}
At present, the designing of a power supply system for mine sections is performed in accordance with obsolete regulatory documents made in the early $90 \mathrm{~s}$ of the 20th century. This slows down the implementation of the 'digital mining operation' concept and prevents the full potential for energy savings from being realized. At the same time, development of digital technologies makes the issues of computer simulation of the power supply system of the coal mine sections urgent. Simulating computer modelling is required to develop measures for increasing the efficiency of the power supply system of operating coal mines as well as for designing new coal mines. The article offers the methodology of forming simulation computer models for evaluation of the energy efficiency of the power supply system for a coal mine section. To ensure the correct development of active and reactive power consumption profiles, it is proposed to use scenario approach to modelling dynamic processes. As an example of using the proposed approach, one of the scenarios for the operation of power supply system of a mine section at one of the coal mines of Kuzbass is reviewed here. The proposed approach to scenario modelling of operating modes of a mine section ensures the correct modelling of dynamic processes for the subsequent assessment of the effectiveness of the use of intelligent devices for controlling the flows of active and reactive power, which will make it possible to accurately assess the effect of FACTS devices on the level of active power losses, as well as the quality indicators of the electrical energy. The proposed methodology can be used in the development of computer-aided design systems for the design of energy-efficient power supply systems for extraction areas.
\end{abstract}

\section{Introduction}

Development of underground coal mining is characterized by constant improving of mining machinery and mining processes (see Fig. 1):

- In the 40s-60s of the 20th century, underground mines had quite a low level of automation. Shearers and chain conveyors were just beginning to be widely introduced. At

\footnotetext{
*Corresponding author: nepshafs@,kuzstu.ru
} 
the same time, in the mines, the voltage level in the power supply system did not exceed $660 \mathrm{~V}$.

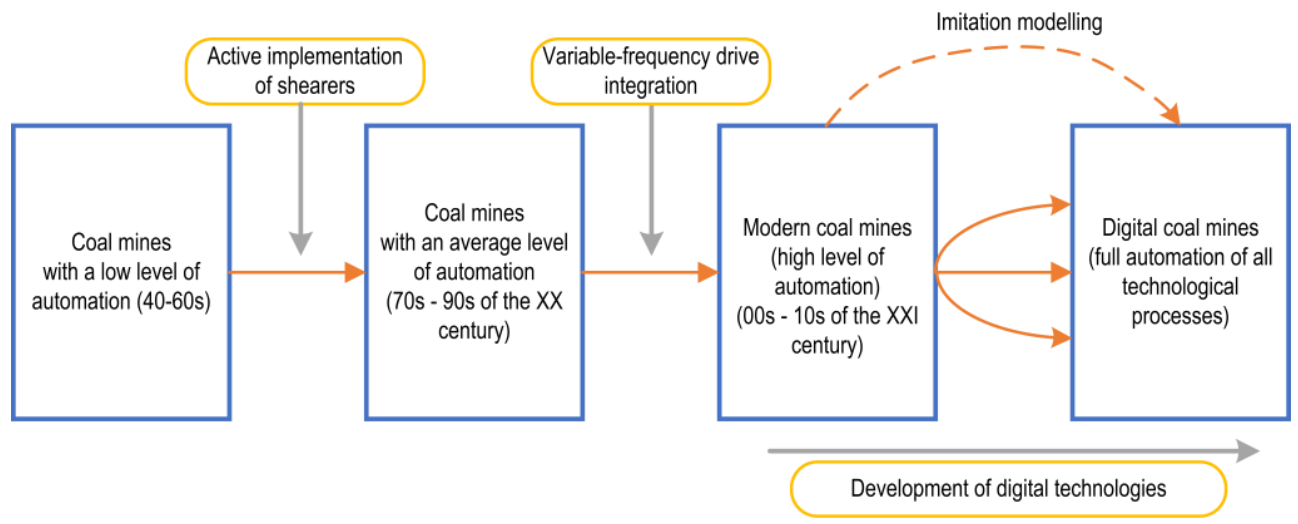

Fig. 1. Development of underground coal mining.

- In the $70 \mathrm{~s}-90 \mathrm{~s}$ of the 20 th century, the comprehensive mechanization

of coal extraction was completed. At the same time, a frequency electric drive was gradually developed, which ensured an increase in the efficiency of underground coal mining. Equipment with a nominal voltage of $1140 \mathrm{~V}$ appears in coal mines.

- In the $00 \mathrm{~s}-10 \mathrm{~s}$. of the $21 \mathrm{st}$ century, most coal mines have a high level of automation, there are automated control systems that allow you to control the main technological processes from the surface. Shearers with a rated voltage of an electric drive of $3300 \mathrm{~V}$, as well as belt conveyors with an electric drive of $6000 \mathrm{~V}$, are being actively introduced.

Nowadays, the coal industry is at the stage of digitalization, as a result of which the maximum automation of all technological processes should be achieved in mines.

In June 2020, the Government of the Russian Federation approved the programme for the development of the coal industry until 2035 [14]. One of the key areas of the programme is the implementation of Industry 4.0 concept with a subsequent increase in equipment efficiency by 1.8 times and labor efficiency by 3 to 4 times.

In China, they are widely engaged in the intellectualization of the processes [1] associated with the design and operation of coal mines. The paper [2] identifies 3 stages of development of the coal industry: Industry - 3.0, 4.0, and 5.0. The stage Industry 3.0 corresponds to a decrease in the number of personnel, a decrease in emissions into the environment, and it has already been practically implemented at most of the coal mines of Kuzbass. The stage Industry 4.0 assumes near-unmanned coal mines with practically no emissions into the air, while Industry 5.0 corresponds to full processing of coal in the underground part of the coal mine, no personnel in the underground part of the mine and no emissions into the air. In the paper [4], the term "intelligent coal mining" was proposed, the work [3] proposed the term "sustainable mining, green mining".

The paper [7] discusses the issue of creating a technological platform for creating digital mining enterprises. It notes that the design process of coal enterprises is accompanied by a large amount of documentation, which leads to problems with document versioning and possible errors. All this negatively affects the pace of digitalization of mining enterprises.

In terms of the electrical complex, the decrease in the rate of digitalization is due to the fact that, despite the increase in power supply per production unit, the design of power supply systems (PSS) for the extraction working areas of coal mines is still carried out in accordance with the obsolete "Instruction on the design of electrical installations of coal mines, open-pit mines, processing and briquette factories"(1993) (hereinafter referred to as the Instruction). This Instruction was developed in the $60 \mathrm{~s}-80 \mathrm{~s}$ of the twentieth century and 
therefore it does not take into account the specific features of the electrically-powered machinery for the working areas of modern coal mines. As a result, technologies for intelligent control of the active and reactive power flows are still poorly used in coal mines. This does not allow the full realization of the potential for improving energy efficiency.

In the literature, there are a number of simulation models of working areas for coal mines and associated equipment used for different purposes:

- the article [17] provides the rationale for the development of simulation computer models for the executive bodies of shearers and road-headers;

- in the article [18], the problem of determining the power and kinematic parameters of the aquifer executive bodies of the geokhod is considered and the variant of solving the problem in the MatLAB Simulink environment is proposed;

- the article [19] briefly describes the principles of implementing the model of the geokhod aquifer executive bodies in the MatLAB Simulink environment;

- the article [20] provides a rather detailed description of the technological process at the production face, the model gives out KPI in the form of the volume of coal mined and the distance travelled by the shearer;

- the document [21] describes a three-dimensional model developed in the MTSS environment. The conclusion is made that from a certain moment an increase in the length of the face does not lead to an increase in productivity;

- the article [22] reviews simulation models of various subsystems of a coal mine (belt conveyor subsystem, pumping subsystem, face area subsystem) using an interactive 3D modelling environment. The proposed modelling environment provides fast modelling using element libraries in interacting with external systems;

- the article [23] describes a simulation model of a fully automated production face of a coal mine. The model makes it possible to determine the emission of methane taking into account ventilation and the operating mode of mining equipment;

- the dissertation [24], using discrete modelling, investigates the efficiency of the face complex and identifies the parameters that have the greatest impact on the productivity of the working area.

It should be noted that the above papers did not study the dynamics of reactive power consumption by mining equipment of the production area. Thus, their results do not allow assessing the energy efficiency of the power supply system for the production area.

In connection with the above, it is required to develop simulation computer models of the electrical complex of extraction areas, which allow the formation of a methodology for designing of power supply systems for a digital mining enterprise.

It should be noted that computer simulation is necessary to create adequate mathematical models that allow, together with the information model, to ensure the creation of a digital twin [15] sufficient to perform the following actions: reliable display of the state of the object in real time; reliable prediction of object behavior under normal and abnormal operating conditions; reliable generation of controlling actions on the object.

\section{Setting the problem}

The power supply per mining equipment and the technological features of coal extraction significantly affect the cost of production. Therefore, it is necessary to pay special attention to the extraction area when developing energy efficiency measures to reduce the cost of coal mining. Fig. 2 shows a block diagram of the location of mining equipment and the power supply system of the extraction area at one of the coal mines of Kuzbass. The main resource consumed by mining equipment is electricity. The extraction site receives power from an underground distribution point (RPP), from which cable lines come to mobile district underground substations (PUPP). PUPP reduce the voltage from $6000 \mathrm{~V}$ to the rated 
voltage level of mining equipment. Until recently, the rated voltage of the equipment did not exceed $1140 \mathrm{~V}$, however, the electric drive of modern shearers already has a nominal voltage of $3300 \mathrm{~V}$. There are also belt conveyors with an electric drive of $6000 \mathrm{~V}$.

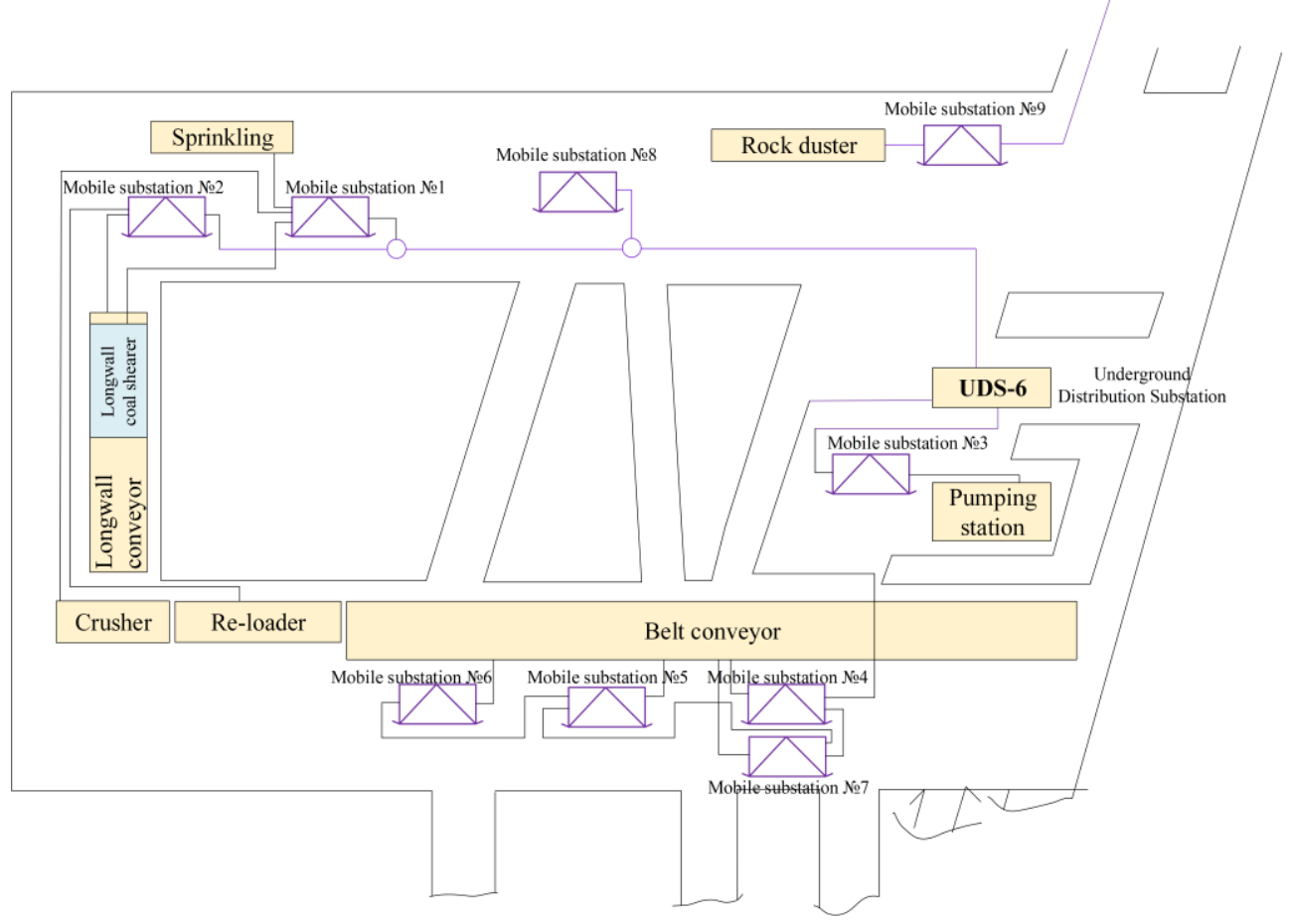

Fig. 2. Block diagram of the location of mining equipment and the power supply system of the extraction area at one of the coal mines of Kuzbass.

An increase in the voltage level is caused by an increase in the energy intensity of the equipment of the extraction area, the need to reduce losses in cable lines, as well as lower weight and overall dimensions of high-voltage motors of comparable power.

The data [16] show that the extraction area of a coal mine has a high power supply per production unit. At the same time, even at the rated load of the equipment, the consumption of reactive power is very significant.

In addition, due to the predominant motoring load operating in intermittent mode, it is necessary to take into account transient processes that have a significant effect on the consumption of reactive power. The effectiveness of this approach has been proven in the works of V.V. Dabarova [9], Mareio M. de Oliveira [10], Z. Ming [11], Y. Lee, L. Liudvinavicius [12], etc. Also, it is necessary to assess the efficiency of high-speed devices for controlling the flows of active and reactive power.

\section{Methodology for modelling the electrical complex of a coal mine}

To simulate the electrical complex of a coal mine, the authors propose to use the algorithm presented in the figure below (Fig. 3). Simulation computer models are needed to assess the indicators of the energy efficiency of PSS in coal mine extraction areas, as well as to assess the technical and economic feasibility of using reactive power compensation devices (RPC), active filter compensating devices (FCU), FACTS devices (static thyristor 
compensators, STATCOM, dynamic voltage distortion compensators (DVDC)), and electric energy storage systems in mine conditions.

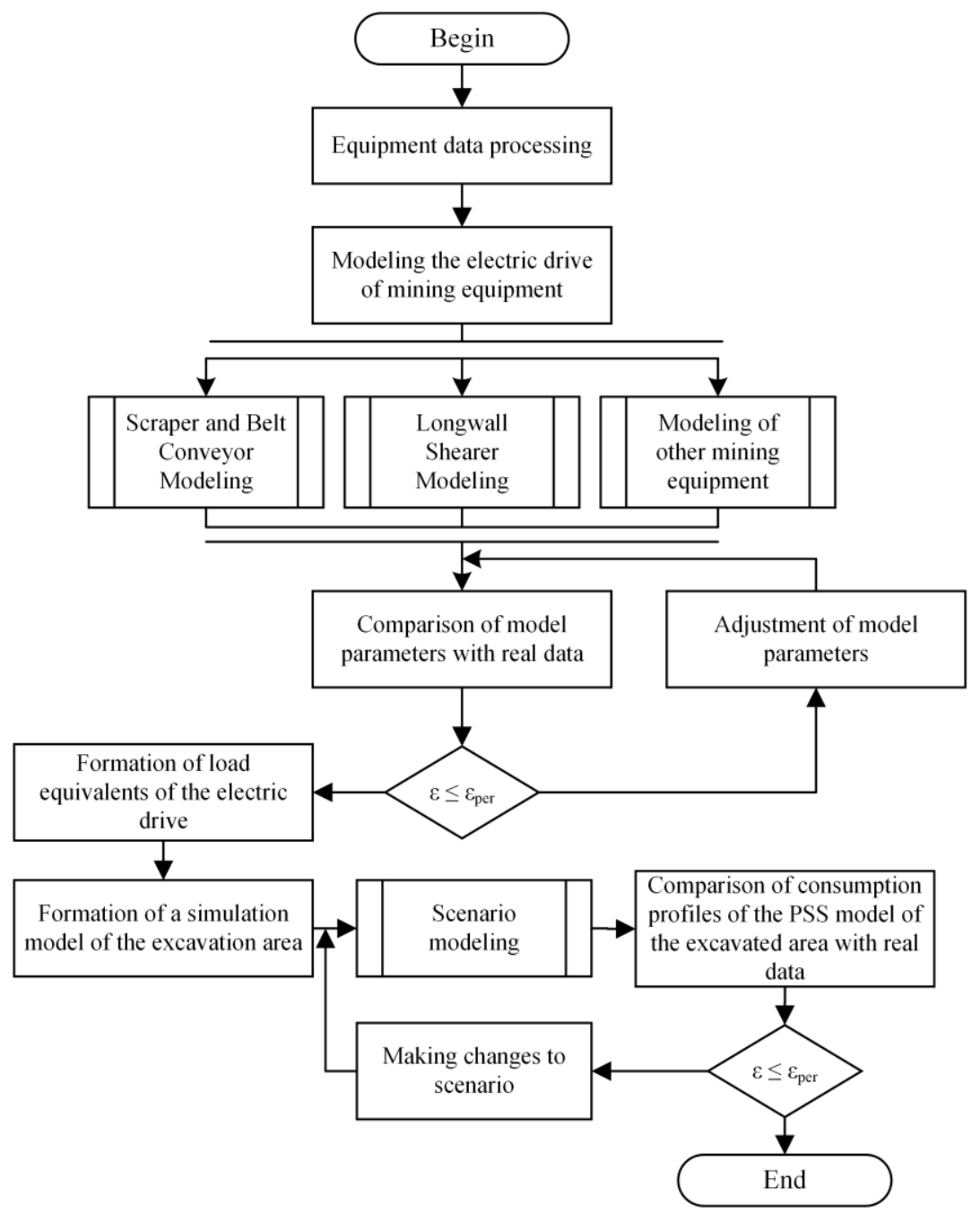

Fig. 3. Block diagram of algorithm of the electrical complex of a coal mine model.

The formation of a simulation model of the electrical complex includes implementation of the following phases:

1) Collection of the data on the equipment required for modelling of the electric drive of the key mining equipment:

Shearer. Simulation of the resistance torque of the shearer cutting electric drive is carried out by calculating the cutting forces of the cutters of the cutting drum depending on the angle of the drum rotation.

To perform this calculation, information is required on the design and technological parameters of the shearer and the mining and geological parameters of the seam being developed. The random nature of the change in the coal resistance to cutting is taken into account by the average value and dispersion of the coal resistance to cutting of the seam 
being developed. To simulate the resistance torque of the feed electric drive, data on the mass of the shearer and the angle of seam inclination are required [25].

Chain and belt conveyor. Simulation of the resistance torque of the traction unit of chain and belt conveyors is carried out on the basis of the representation of the traction unit as a set of elementary dynamic links, which represent some inertial mass connected with neighboring masses using a linear elastic-dissipative element.

The model development requires the data on conveyor length; the mass of the section of the traction body; the coefficients of stiffness and resistance of the links of the traction body; diameter, weight, stiffness, and resistance coefficients of the drive drum; movement resistance coefficients; and traffic parameters. For belt conveyors, it is also necessary to know the weight of the load of the tensioner.

Crusher, stage loader, sprinklers. Simulation of an electric drive for the above elements is made in a simplified way, i.e. without a detailed consideration of the factors impacting the load torque at the electric motors shaft.

The simulation model of each electric drive of the mining machinery includes gear reducers and electric motors. The following data are required for the gear reducers: - gear ratios; moments of inertia; stiffness and resistance coefficients.

To simulate an electric motor, passport parameters are sufficient (rated power; rated voltage; power factor; efficiency; number of pole pairs; multiplicity of starting torque and current; moment of inertia; slip).

2) Simulation of mining equipment. At this phase, the simulation models are created in a specialized simulation environment MATLab Simulink.

3) Comparison of simulation results with the actual data. The simulation results are compared with the actual measurement results, as a result, the average deviation value of the active and reactive power consumption curve from the real values $(\varepsilon)$ is determined. If the value $\varepsilon$ is less than or equal to the permissible value $\varepsilon$ доп of the simulation error, then the simulation results are recognized as satisfactory and suitable for the further formation of the simulation model for the PSS of the coal mine extraction area. Otherwise, changes are made to the model of the electric drive until the simulation errors correspond to the permissible values.

4) The load equivalent of the electric drive for the mining machinery is generated in case a great amount of simulation models prevent provision of the required time for simulation. The load equivalent is a function of the consumed active and reactive power of the model time.

5) Generation of extraction area simulation model. On the basis of the generated models of the electric drive, a model of the electrical complex of the extraction area of a coal mine is formed.

6) Scenario modelling. To perform scenario modeling, it is required to monitor the operation of electrical equipment in order to subsequently simulate a set of modes characteristic of specific stages of the technological process. In the absence of such data, you can use the work planogram. The purpose of the simulation is to establish a relationship between the mode of operation of electrical equipment and technological processes.

7) Comparison of consumption profiles of the extraction area PSS with the actual data. Real measurement data are compared with simulation results. As a result, the simulation error is determined, which should not exceed the permissible values.

8) Entering changes in the scenario. In case of a significant simulation error, changes are made to the simulation scenario (the changes are made to start / stop time of the equipment and the duration of its operation in a specific mode). 
The end result of the simulation is the formation of a simulation model of a high degree of reliability that is suitable, inter alia, for the subsequent formation of a digital twin of the coal mine electrical complex.

Scenario approach to generation of simulation models. The scenario approach to the generation of simulation models consists in a step-by-step description of the operating modes of electrical equipment in the course of the technological process. To do this, first, technological maps and work planograms are studied during operation of a working face under load.

At the extraction area, the technological process is taking place around the clock and is divided into 4 shifts: 1 st shift (repair, usually from 7-00 to 12-00), $2^{\text {nd }}$ to 4 th shifts (operation from 12-00 pm to 7-00 am).

During the repair shift, the miners of the working face perform the maintenance of the equipment, then the technological process of coal mining begins, which remains almost identical during the $2^{\text {nd }}$ to the 4 th shifts. Note that due to a significant number of random factors, real graphs of operating modes of mining equipment may differ from the planogram.

Thus, the operation of the extraction area can be subdivided into the following key scenarios: a repair shift and a working shift.

A repair shift includes the following sub-scenarios:

1) Shutdown of mining machinery;

2) Repair and maintenance of equipment (periodic switching on/off of the equipment to check it).

3) Shift turnover.

The operation shift includes the following sub-scenarios:

1) Start up of the mining machinery (prior the $2^{\text {nd }}$ shift)

2) Cutting by the shearer

3) Coal extraction by the shearer (a relatively constant load of the shearer in comparison to the start-up mode)

4) Sweeping of the shearer path and advancement of the face conveyor (stopping the machinery).

5) Shift turnover.

The description of sub-scenario "Start-up of the mining machinery" is given below.

1. Start-up of the belt conveyor (simultaneous start-up of the drive stations). Condition - belt conveyors are started.

2. Crusher start-up.

3. Stage loader start-up.

4. Chain conveyor start-up.

5. Shearer start-up (Start-up of cutting drive, start-up of feed drive).

6. Shearer cutting.

7. Coal extraction by shearer.

8. Cutting drive shutdown.

9. Shearer moving forward and sweeping the floor.

10. Repeat items 1 to $9 \mathrm{n}$ - times.

Further, the scenario is detailed to determine the specific start time of the electric drive in order to ensure the adequacy of the simulation computer model.

\section{Areas of further studies}

Further on, it is planned to use the proposed methodology to create detailed simulation models of the electrical complex of a coal mine section area in order to test hypotheses about the feasibility of using intelligent devices for controlling the flows of active and reactive power. In addition, the proposed approach can be used to expand the functionality 
of existing SCADA systems in terms of creating digital twins that support decision-making and assess the effect of using new technologies.

\section{Conclusions}

The rapid digitalization of coal mining enterprises requires the development of simulation modeling methodology in order to obtain computer models of a high degree of reliability. Such models can be used during the design and operation stages.

The methodology presented in the article makes it possible to form a simulation model sufficient for further analysis of the feasibility of changing the topology of the power supply scheme, as well as assessing the effectiveness of the use of FACTS devices.

The proposed approach to scenario modelling of operating modes of a mine section ensures the correct modelling of dynamic processes for the subsequent assessment of the effectiveness of the use of intelligent devices for controlling the flows of active and reactive power, which will make it possible to accurately assess the effect of FACTS devices on the level of active power losses, as well as the quality indicators of the electrical energy.

In addition, the proposed methodology can be used in the development of computeraided design systems for the design of energy-efficient power supply systems for extraction areas.

This work was done with the support of the Scholarship of the President of the Russian Federation on State Support of Young Russian Scientists No. MK-236.2020.8 and MK-86.2021.4.

\section{References}

1. R.Y. Zhong, X. Xu, E. Klotz, S.T. Newman, Engineering, 3 (5), 616 (2017)

2. X. Heping, G. Feng, J. Yang, J. China Coal Soc. 42 (3), 547 (2017)

3. G. Wang, Y. Xu, H. Ren, Int. J. Mining Sci. Technol. 29 (2), 161 (2019)

4. M. Qian, J. Xu, J. Wang, J. China Coal Soc. 43 (1), 1 (2018)

5. G. Wang, F. Liu, Y. Pang, H. Ren, Y. Ma, J. China Coal Soc. 44(2), 349 (2019)

6. G. Wang, G. Zhao, H. Ren, J. China Coal Soc. 44 (1), 34 (2019)

7. J. Wang, L. Bi, L. Wang, M. Jia, D. A. Mao, Appl. Sci. 9, 5373 (2019)

8. Y. Wu, M. Chen, K. Wang, G. Fu, Safety Science (2019)

9. V.V. Dabarov, Abstract of the thesis of the candidate of technical sciences (2013)

10. M.M.de Oliveira, M. Halonen, 2016 IEEE PES T\&D-LA, 1 (2016)

11. Z. Ming, T. Bo, Z. Shuang-feng, Indonesian Journal of Electrical Engineering and Computer Science, 11, 4523-4529 (2013)

12. L. Yunhwan, S. Hwachang, Sustainability, MDPI, 11(2), 1 (2019)

13. L. Liudvinavičius, Transport Problems, 13, 59 (2018)

14. Order of the Government of the Russian Federation of 13.06.2020 N 1582-r.

15. V.V. Okolishnikov, A.A., Ordin, S.V. Rudometov, DICR-2019, (2019)

16. K.N. Kopylov, MIAB, 12, 40 (2016)

17. A.V. Babarykin, N.K. Schneidmiller, A. A. Khoreshok, XI All-Russian scientificpractical conference with international participation "Young Russia" (2019)

18. V.V. Aksenov, A.A. Khoreshok, K. A. Ananiev, A. N. Ermakov, MIAB, 2 (2016)

19. V.V. Aksenov, A.A. Khoreshok, K. A. Ananiev, A. N. Ermakov, Bulletin of the Kuzbass State Technical University, 1, 77 (2016)

20. D. Cai, E. Baafi, I. Porter, Faculty of Engineering and Information Sciences - Papers: Part A. 214 (2013) 
21. V.V. Okolnishnikov, MACISE, 202 (2020)

22. V. Okol'nishnikov, S. Rudometov S. Zhuravlev, Engineering, Technology \& Applied Science Research 6, 993 (2016)

23. V.V. Okolnishnikov, A.A. Ordin, S.V. Rudometov, Optoelectron.Instrument.Proc. 55, 383 (2019)

24. Y. Enver, Thesis for the degree of master of science in mining engineering (2018).

25. K.A. Ananiev, A.V. Babarykin, A.N. Ermakov, Proceedings of the VI International Scientific and Practical Conference, 533 (2018)

26. R. Muminov, G. Rayhanova, D. Kuziev, Ugol', 5, 32 (2021)

27. A. Khoreshok, K. Ananiev, A. Ermakov, D. Kuziev, A. Babarykin, Acta Montanistica Slovaca, 25, 70 (2020) 